\title{
Information Technology and University General Education Reform
}

\author{
Yijing $X U^{1, a}$ \\ ${ }^{1}$ General Education Center, Beijing Normal University Zhuhai Campus, China \\ a45443202@qq.com
}

Keywords: Information Technology. Teaching reform. Curriculum reform of General Education.

\begin{abstract}
Nowadays in Mainland China, one of the difficult problems of curriculum reform of the Universities is how to improve the efficiency and effect of education availability. This paper takes the course of "The Piano Western Culture" as an example, tells about how to apply the modern information technology to the education reform, so that to improve the teaching effect and experience for realizing the individualized educating.
\end{abstract}

\section{Introduction}

In 1999, in the 3rd National Education work conference, the State Council has made the decision of "About deepening the reform of education and comprehensively promoting the quality-oriented education ", quality-oriented education advancing rapidly in different educational units in our country. Especially in the area of higher education, the cultural quality-oriented education plays an important role in promoting college education teaching reform, improving the quality of personnel training, improving the cultural taste in an university, cultivating high-quality talents with all-round development, moral, intellectual, physical, etc. Under the historical background, in November 2011, the research seminars of the college Quality-oriented education in Chinese higher education association were founded. This marked the college quality-oriented education in our country entered into a rapid developing stage. Since then, the college quality-oriented education seminar was held every year by the association and attracted scholars from different cities (including Hong Kong, Macao and Taiwan) and countries.

In recent years, developing and promoting quality-oriented education has gained some obvious achievements in China. Experts and scholars came out with the following consensus:

The quality-oriented of education first is a kind of educating thoughts, because it including ideological and moral quality, cultural quality, professional quality, physical and psychological quality. The exploration, research and practice of quality-oriented education, not only relative to the experts, scholars, but also relative to students and parents, and the participation from the people from all walks of life.

The research direction of quality-oriented education includes "quality education and university culture inheritance and innovation", "college quality education mechanism and team construction", "quality education general course system construction", "the exploration of ways and methods of the quality education".

Modern information technology makes the teaching methods becoming more diversified.

Big data processing and data mining technology is bringing a huge change to the college quality-oriented education and reform.

\section{The difficulties in the current teaching reform in colleges and universities}

As mentioned above, both experts and scholars, or the ordinary university teachers and students by education, to promote the significance of quality education and the way forward, have made it clear that down and get consistent approval, but in the concrete implementation process, there are many problems and objections.

How to improve the relationship of general education and professional education. 
The setting of curriculum standard (from "elite education" to "mass education", will become the "popular science education").

How to deal with the teaching of "teaching" and "learning" relationship.

After the implementation of teaching reform in colleges and universities, how to evaluate real and effective course teaching effect, as well as the quantitative standard is what.

The state of various forms of education and teaching evaluation, can you find more satisfactory new ways and methods.

\section{The adoption of modern information technology is one of the effective ways to solve the problem}

Although some experts and scholars are debating the origins of the quality education and general education, meaning, and from which belongs to the education schools "theoretical problem", and in teaching the first line of education workers, has been different, their respective education conducted fruitful work. In domestic widely attention on popular search engines on the website "baidu", quality education has more than 150000 articles, general education and teaching reform, there are more than 15000 articles.

Beijing normal university, I believe, Chinese General Education Research Center director professor De-sheng Wang, clearly put forward for the first time in 2007: general education of China's colleges and universities should be according to the five modules (i.e., the humanities, natural science, social science, artistic accomplishment and practice skills) strengthen the construction of course system, and should be implemented "SanJin class (i.e., the Chinese learning into the classroom, the frontier of science and technology into the classroom, world classics into classroom) classification, is a comprehensive understanding and implementation of the general teaching of good position. The position in academia also caused widespread concern and high praise.

In today's rapid development of science and technology today, how to use and the use of modern information technology, promote the quality of college education, how to work in practical teaching, for the fruitful work, and to summarize the experiences and lessons of the teaching, is our each college teachers should consider.

The application of modern information technology in teaching, mainly reflected in: electronic teaching, remote teaching, multimedia teaching, online teaching, network (mobile), and self-organizing learning, blended learning, social learning, and class, micro courses and various forms of launch, is inseparable from the development of modern information technology. It can be said that "modern education technology" is dependent on the modern information technology and exists; it is only the application of modern information technology in education field.

\section{General instance teaching course reform}

The characteristics of general courses teaching classes. Most of the University general education courses are for the whole school selection. Every elective classes and grade's student members, may come from different professional, from different grade, the study is based on "shades" (mainly refers to the study in middle school stage, the resulting learning opportunity is different, different levels of secondary education), the learning ability of students has bigger difference (rather than in the middle school is "heuristic teaching" is still "cramming teaching"), the students of the purpose of this course is different, the pursuit of the learning goals (effect) is also different. Beijing normal university zhuhai campus learning "western piano culture" (bilingual education) course, the statistics of the basic situation of the students, is as above situation.

\section{The teaching way and method.}

The guarantee of teaching environment. Speech classroom is equipped with modern teaching equipment. Everyone 1 microcomputer and high-fidelity headphones, convenient student voice session; HD projector and screen configuration, Convenient teacher in the classroom can playing course ware to own, the number of students in each class control between 50 to 60 people, ease of class management. 
Teaching conditions of improve. School office configuration digital network teaching platform, in order to promote students' online to learn more about this course on campus; the teachers and students are between the E-mail communication through, homework assigned by the teacher and student assignments submitted, the before class of teaching content download (data), And of the processing on classroom attendance and so on.

The arrangement of the teaching course. In order to adapt to the needs of different students, Teachers in curriculum section the teaching content on the "delay" and "down" is necessary. Namely: expanding introduce relevant basic knowledge, appropriate introduction of the development of professional knowledge, the select " appropriate " section and the "basic knowledge" section, have give certain professional "depth" section selection to have "special needs" of the students learning, It is one of "personalized teaching" method.

The teaching materials and auxiliary learning materials. In order to develop students' knowledge, introduce more reference books, this is raises the student good reading habits, and improve the college students in the higher education stage, this is must have the ability to study independently One of the ways.

The auxiliary learning materials. To provide more multimedia teaching materials and to guide the student to study, this is for art course for learning necessary, the human visual and auditory stimulation for the sensory function, to have stronger effect.

The arrangement of learning outside the classroom. Obviously, the classroom teaching time and content, it is difficult to achieve and satisfy with the pursuit of learning for this part of the student's requirements. The arrangement of the teacher and guide students in their spare time more and broader learning content is necessary. This is one of "personalized teaching" method.

\section{The reform of the ways and methods about students' performance assessment}

When after the course, the teaching achievement evaluation, and the also is an important part in teaching, its important content should be divided into the following three aspects. One is the assessment method, the second evaluation criteria; the third is the purpose of.

Evaluation way. This way of assessment is not "attendance plus the mid-term exams and daily assignments and final exam", this in most colleges and universities are widely used in the conventional way. But we have to stand on a higher starting point, come to carry out the performance evaluation way reform : the "students self-evaluation and Group evaluation of group discussion ,finally decided by the teacher" a new model .The first kind of "conventional method" we no longer discuss here, talk about the organization process of the second kind of way. At the end of the semester, the teacher on the course on the summary in basis of "complex operation" decorate, of course, complex operation content can according the teachers to the different categories for teaching content, adopt different contents, art, comprehensive report, investigation, analysis, research papers and so on all is possible. Below, and I'm in the paper for example, talk about its particular way.

The topic of thesis can be optional, but the theme and content must be related to this course, if "digress From the subject", whether intentional or unintentionally, the result is "flunk".

One of the contents of the thesis, the first is the course of this semester for a comprehensive summary, and then you can have a profound understanding to him one of the key issues for discussion.

You must Have to talk about in the learning this course, the harvest or superficial, even not do understand of the content or the chapter.

To teachers lecture Outside of content, whether to have creative thinking or have a different point of view and ideas.

If there are other than learning tasks assigned by the teacher practice and practice process.

For their own learning, I what are the harvest in this course? (Note: each student's learning different, harvest certainly is not the same, on the basis of teachers in evaluation scores to give objective evaluation, completely consistent standard inappropriate).

Objective self assess their learning scores and Tell yourself how many points are based on what reason. 
To Teacher's teaching methods, teaching content and so on constructive Suggestions are put forward.

\section{The assessment method.}

After the "self assessment" link, if you can "Group evaluation of group discussion" is better. One way is will be each your students "self assessment" released to the public, by all the students to give him to comments and evaluation. Another approach is to choose the assessment team (or myself recommended), by the members of the group to give them comments and evaluation. Each student's learning basis, on the different basis for his harvest is also different, teachers should give objective evaluation of the rating scores, and completely consistent standard is inappropriate. And then form the text materials, submitted to the superior department in charge of teaching for the record.

The purpose of performance appraisal and evaluation. Examination and appraisal, in go over is a continuation of the final, the go over is a summary to this course, the summary is to consolidate and improve the learning of this course. Since it is, In the past of that kind of stiff, bind teachers and students hands and feet, between unfavorable to students' learning, and examination and evaluation method is not appropriate, the method of quality education today, must be improved.

\section{What we should do next}

Through the survey of students' daily study and life behavior analysis and control, presumably or predict the late recently even university students learning situation. Therefore, according to the students of different stages, goodwill and purposeful education and guidance to students, the right to correct the problems we found in advance, so that the students can be adapted in a timely manner in learning and life behavior was improved, and the final at the end of university life, the most effectively to harvest is the big data processing and data mining application in the education field, application in the quality education, applied to the importance of general education curriculum reform.

\section{References}

[1] Guo Dacheng and PangHai Que, The quality of university education and university education reform - 2015, Higher education press, 2015

[2] Guo Dacheng and PangHai Que, The quality of university education and university education reform - 2012 essays on top quality education, Higher education press, 2013.

[3] Guo Dacheng, The research and exploration of the leading system of colleges and universities Beijing university of science and technology press, 2014. 